\title{
Investor Sentiment in Stock Market: A Case of Pakistan Super League in Pakistan Stock Exchange
}

\author{
FURQAN ULLAH \\ Lecturer Government College of Management Sciences, Peshawar, KP Pakistan \\ furqan815@gmail.com \\ MUHAMMAD ASIF \\ Assistant Professor, Department of Management Sciences, City University of \\ Science and Information Technology, Peshawar \\ MUHAMMAD ZAHID \\ Assistant Professor, Department of Management Sciences, City University of \\ Science and Information Technology, Peshawar \\ FAIZA MEHREEN \\ MS Scholar, Department of Management Sciences Department, \\ City University of Science and Information Technology, Peshawar
}

\begin{abstract}
This study investigates whether sentiments play any role while investors make financial decisions which results in the stock returns. The paper analyzes the major two sports events (2016-2017) of Pakistan Super League (PSL). The study utilizes the stock market data from Pakistan Stock Exchange (PSX)-100 index for the period of two financial years starting from June 2015 to July 2017. PSL T20 data is collected from the official PSL website. The empirical results of the studyshow that PSL sports events are highly statistically significant and imply that the events trigger investor sentiments (optimistic and pessimistic behaviors) in the PSX. When the whole PSL games were played on United Arab Emirates (UAE) grounds in 2016, later on, which badly affected the investor moods and resulted in a negative abnormal return in PSX-100 index. While in case of PSL event in 2017, in which only final match of the event was held in Lahore, Pakistan and resulted in a positive abnormal return in PSX-100 index. The study provides implications for different authorities such as Pakistan Cricket Board (PCB), PSX and other development authorities in order to promote such activities for the overall economic and social benefits. While founding no previous studies concerning the subject in the Pakistani context, the Scholar selected the issue to conduct a research and make a considerable contribution for investors in Pakistan with respect to PSL events and its impact on PSX. Keywords: Investor Sentiments, Stock returns, behavioral finance, Pakistan Super League, Pakistan Stock Exchange
\end{abstract}

Keywords: Investor Sentiments, Stock returns, behavioral finance, Pakistan Super League, Pakistan Stock Exchange 


\section{Introduction}

A growing body of literature has investigated a link betweensports events and its impact on the stock market returns. These studies find that stock market reacts sharply to sports events. One might expect that sports events are a noneconomic phenomenon and it does not affect the stock prices but behavioral finance suggests that big sports events affect the sentiments of the viewers as well as the investors which lead to "mood swings" in the stock market, and it is reflected in the asset prices(Mishra \& Smyth, 2010).In many countries, both men and women are emotionally engaged in watching sports events and it has become a part of the cultures. Many times, spectators are seenmourning a loss and celebrating a victory in sports. This phenomenon implies to investors in markets. Ultimately, this scenario poses a million dollar question that whether or not the investors' emotions affect the stock market returns(Rees \& Bersem, 2010).Stock markets play a vital role in the development of a country and hence it is called the backbone for the growth of the country. Stock markets are vulnerable to different macro and microeconomic variables which leads to upward and downward trends in the stock market. Behavioral finance is the field of study where the cognitive effects are investigated asStatman, (1999) argues that investors sometimes make such decisions which produce cognitive errors and results in prices which are quite different from the pure rationality of an efficient market. The scholars mean that those events which trigger mood and physical or emotional state of investors can significantly affect the stock prices.

Investor sentiment is one of the indicators in behavioral finance which has a greater impact on the stock market returns. Several studies document the links between investor sentiment and stock returns. Kaplanski, Levy, Veld, \& VeldMerkoulova, (2015) investigate that happiness and unhappiness of the investor's matters in the stock market and find that non-economic factors really affect the stock market returns and the risk expectations associated with the securities. Behavioral finance is the marriage of psychology and finance where the valueexpressive characteristics of the securities prices are investigated as Statman, (1999) says that in standard finance rational prices only reflect the risk related characteristics and not the value-expressive characteristics, such as investor sentiments. Behavioral finance has shown that value expressive characteristics of the securities contribute to both investors' moods and asset prices. That is why investor sentiment plays an important role in determining the reactions of the stock market returns.

Investors are usually busy in the stock market on the basis of their attention regarding how much they pay to different securities as Schmidt et al., (2013) follows the rational attention theory and tests how fluctuations in the attention of the people affect the stock market. The scholars find that investors rationally allocate their attention in the stock market. Behavioral biases have a profound impact on the asset pricing documented in psychology research. Over the last decade, this research has undergone a significant expansion and is comprehensively reviewed by Hirshleifer, (2003), Shiller, (2015). Investor sentiment and stock returns are profoundly studied by (Guy Kaplanski and Haim 
Levy, 2010, Ryu, Kim, \& Yang, 2017, Geyer-Klingeberg, Hang, Walter, \& Rathgeber, 2017, Siganos, Vagenas-Nanos, \& Verwijmeren, 2017).

Many major T20 cricket leagues are established across the globe and got very much popular during the last decades. The names of the league and countries who started and the corresponding years are provided in the following Table 01 .

Table 1: T-20 Leagues across the World

\begin{tabular}{|c|c|c|c|}
\hline League name & Country & $\begin{array}{l}\text { Year of } \\
\text { starting }\end{array}$ & $\begin{array}{l}\text { Total } \\
\text { teams }\end{array}$ \\
\hline 1. Big Bash League (BBL) & Australia & 2011 & 8 \\
\hline 2. Pakistan Super League (PSL) & Pakistan & 2016 & 5 \\
\hline 3. Indian Premier League (IPL) & India & 2008 & 8 \\
\hline 4. NatWest T20 Blast (NWB) & England & 2003 & 18 \\
\hline $\begin{array}{l}\text { 5. Carribean Premier League } \\
\text { (CPL) }\end{array}$ & West Indies & 2013 & 6 \\
\hline $\begin{array}{l}\text { 6. Bangladesh Premier League } \\
\text { (BPL) }\end{array}$ & Bangladesh & 2012 & 7 \\
\hline 7. Global T20 League* & South Africa & 2017 & $8 *$ \\
\hline
\end{tabular}

*Global T20 League: the teams are not yet decided finally.

Source: http://www.espn.in/cricket/story/_id/20215459/the-lowdown-all-t20-

leagues

A major sports event of T20 attracts players, media, spectators, and investors. PSL is also a T20 scheme of Cricket which is enthusiastically viewed in Pakistan. This major sports event generates sentiments and influences the behavior of the individual as well as the investor's decision-making process. Good or bad mood leads to high or low investment in the stock market.

Literature supports the impact of investor sentiments and sports events on the stock market returns. Evidences exist from previous studies, generally of investor sentiment by Jiang et al., (2017), Balcilar et al., (2017), Ryu et al., (2017), Sun et al., (2016) and specifically of sports sentiments by Edmans et al., (2007), Chang et al., (2012), Kaplanski and Levy, (2010), Bracewell et al., (2017), Mishra \& Smyth, (2010), Fung et al., (2015), Refai \& Eissa, (2017) and at lastKlein et al., (2009), Floros, (2010) used the stock exchange index returns to show the association between football matches outcomes and stock exchange index returns, in different countries. In Pakistan, Pakistan Super League event has become very popular and attracted spectators and investors during the first and second season. While founding no previous studies concerning the subject in the Pakistani context, the study selected the issue to conduct a research and make a considerable contribution for individuals and investors in Pakistan with respect to PSL events and its impact on PSX index returns.

Hence, the study attempts to develop a typology of major sports event of PSL in terms of its potential to generate significant economic impact in PSX. Hence, the study has the following research objectives to achieve.

- To explore the reactions of Pakistan Stock Exchange in case of Pakistan Super League events. 
- To know the impact difference between the two PSL events on Pakistan Stock Exchange.

The remaining sections of the paper are literature review and hypotheses development, research methodology, results of the study, followed by discussion and conclusion, and last section covers recommendation for future study.

\section{Literature Review and Hypotheses Development 2.1 Standard Finance versus Behavioral Finance}

When questions raised on the assumptions of the standard finance with respect to the rationality of the investors in their decision-making process, it was the standard finance which relaxed the underlying assumptions of the efficient market hypothesis (Baker, Kent; Nofsinger, 2002). After questions were raised on the standard finance with regards to the market efficiency assumptions, meanwhile behavioral finance incorporated sociology and psychology to show actual agent's behaviors comparative to the agent's behaviors discussed by the standard finance theory (Shiller, 2003, Pompian, 2012). In order to differentiate standard finance and behavioral finance, (Pompian, 2012, pp.13) provided the differentiation in the studies of Statman, (1999) for the two conflicting theories in the following word, "People in the standard finance are rational, people in the behavioral finance are normal".

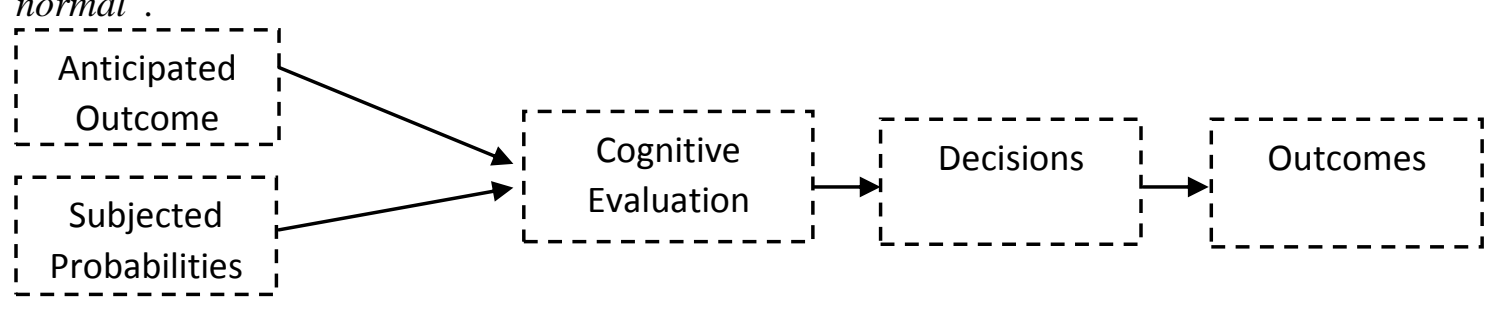

Figure 1: A link between irrational decision making and investor mood Figure 1 depicts that people while decision making weigh benefits and costs of all decisions. People decide outcomes by making an assessment of the tradeoff between risk and benefits. Wright and Bower, (1992) hypothesized that people assign different negative or positive probabilities for future events and the scholar concluded that people in happy mood assign higher positive probabilities to

\subsection{Major Studies on the topic}

events.

Following are the major studies investigated the impact of investors' sentiments on the financial decision-making process of the investors in the markets.

\subsubsection{United States of America Stock Markets}

Chang, Chen, Chou, and Lin, (2012) conduct a firm level analysis to investigate the link between National Football League (NFL) game outcome and return pitfalls of Nasdaq firms and noticed a lower next day return for the locally headquartered firms in case the team loses and consequently, this impact increases with a bad loss or surprising loss. Guy Kaplanski and Haim Levy, (2010)find insignificant coefficients of the annual FIFA World Cup event but the scholars propose that this negative event coefficient spurious may be due to various factors. i.e. previous one or two World Cup years that proved bad in the U.S Stock 
markets and may not account for the outcomes and is resultantly counted as abad outlier. Bracewell, Bracewell, McNamara, and Moore, (2017) discuss the behavioral patterns of the New Zealanders after their national team All Blacks won the Rugby world cup (2015). This study finds that there is a statistically significant positive impact on the mood of the New Zealanders after All Blacks win from Australia.

Hirshleifer and Shumway (2003)focused on the relationship between morning sunshine, stock exchange, and daily market index returnsThe authors said that stock returns strongly positively reacted to morning sunshine.Jiang, Mo, and Nie, (2017) studied investor sentiment and its impact on the stock return in the US economy and no strong evidence were found of the correlation between investor sentiment and stock returns on the short-term scales. Balcilar, Bonato, Demirer, and Gupta, (2017) explored the association between investor sentiment and dynamics of intraday returns of gold market in New York Mercantile Exchange (NYMEX). The authors followed the Financial and Economic Attitudes Revealed by Search (FEARS) index as an investor sentiment variable to show its impact on intraday returns and volatility in the gold market. The authors concluded that investor sentiment significantly contributesto the intraday returns and volatility in the gold market, rather than daily returns in the market. Sun, Najand, \& Shen, (2016)discussed the relationship between high-frequency investor sentiment and stock market reaction.Authors found that returns are mainly driven and reacted to in the stock market by the trading activities of the noise traders.

If political situation remains stable in a country will surely affect the stock market volatility and vice versa. Adjei and Adjei, (2017) investigated the impact of political cycles on the stock market reactions while considering the levels of investors sentiment as a mediating variable. The authors empirically analyzed and found low and improving investor sentiment at the times of Democratic presidential election terms and sentiment was higher and declining at the times of Republican presidential terms. The same study without mediating variable was also carried out by Huang, (1985), Hensel \& Ziemba, (1995).

\subsubsection{European Stock Markets}

Samagaio, Couto, and Caiado, (2009) used a structural equation modeling (SEM) to predict the association between the sports performance, financial performance and stock market reactions during the study period starting from 1995 to 2007 for the clubs of English football in Portugal. The authors concluded that financial performance and sporting performance is strongly and significantly associated with one another. In the meanwhile, the authors explored that it is very clear from the regression analysis that sporting and financial performance is statistically positively correlated with the performance of the stock market returns. By adopting the autoregressive conditional heteroscedasticity (ARCH) the Benkraiem, Ramzi; Le Roy, Frédéric; and Louhichi, (2011) study the effects of sports events on the volatility of listed football clubs. The scholars find that there is a positive association between sports performances and the volatility of listed football clubs and this result was different in case win, draw or loss. 
Floros(2010) studied the association between Athens Olympic Games and Athens Stock Exchange (ASE) and used daily closing values of ASE General index. The author found theinsignificant effect in course of ASE general index but found significant results in terms of OTE index where Hellenic Telecommunication Organization trading and also a positive result for Greek Medallists on the ASE index. The author also concluded that two National sponsors (Alpha Bank, OTE) showed a positive effect against the 2004 Olympic Games. Hence, it is concluded that 2004 Olympic Games produced and showed mixed results in terms of (ASE, OTE) index and different results fornational and international sponsors.

Some of the scholars use a primary mood variable motivated by a psychological evidence as Edmans, García, and Norli, (2007) investigate the soccer results and mood of the investors. The scholars find that stock market goes down as the soccer loses and especially, this change is found high in small stocks where small stocks are very sensitive to investor sentiment. Moreover, this study finds that mood of the local investors has strong links with the performance of the national soccer teams. While Using the even study approach Klein, Zwergel, and Heiden, (2009)test association between football match outcomes and the specific national stock index returns during the study period of 1990 to 2006. The results of this study are quite different from the previous researchers with respect to investors sentiment as it finds no significant results. The scholars incorporate a "surprising" variablein the model but there is no apparent linkage between a specific national soccer teams' win or loss andstock returns prices.

Fung, Demir, Lau, and Chan (2015) used panel data analysis and adopted the Edmans et al. (2007) method for estimation purpose. The authors found significant negative results in case of losing effects. Another research with regards to hosting mega five FIFAsports events and its announcement impact on the stock returnshas been studied by Ramdas, van Gaalen, and Bolton (2015)where they found mixed results of the impact of the announcement of hosting the mega sports events on their respective stock markets returns. Brimicombe and Café (2012) added to literature by studying the association between win or lose during the world cup and domestic violence. The authors showed in their results that during Olympics many spectators used many alcohols and generated more violence during the big matches. More particularly, it was noticed that this violence in home increase when England loses and goes up when wins the match but do not report domestic violence when the match draws.

Sarac and Zeren, (2013) documented an association between soccer performance and its impact on the club's stock returns in Turkey. "The big three" Beşiktaş, Galatasaray and Fenerbahçe clubs were considered in the studies for the periods starting from 2005 to 2012. Through multiple regression models, the authors concluded that there is a positive and significant impact of soccer performance on the all the three club's stock return but the result was found stronger in case of Beşiktaş club's stock return.Namouri, Jawadi, Ftiti, and Hachicha, (2018)conducted a study for G7 countries to predict an association between investor sentiment and the stock market by employing the data from June 1987 to February 2014 and showed results that investor sentiment has a close and 
significant association with stock market returns but this association holds different due to market conditions. Duque and Ferreira, (2005) explored a connection between stock prices reaction and sports performances on the ground. The authors found a significant positive link in case of stock prices fluctuations and performance of the football matches on the ground.

\subsubsection{Asian Countries}

According to Refai and Eissa(2017), the FIFA (2022) world cup announcement is associated with the Doha Stock Exchange (DSE) of Qatar. This study finds that four of the six announcements were found to be strongly associated with the Doha Stock Exchange market volatility. Ryu, Kim, and Yang, (2017) discussed that investor sentiment contributes to asset returns. The scholarsays that individuals, as well as institutions, react negatively or positively to stock returns. By using a Meta-Regression analysis Geyer-Klingeberg, Hang, Walter, and Rathgeber, (2017) addressed conflicting results about the soccer games outcomes on the stock market returns. This course of study determines that the negative reactions of the stock returns are presented exaggeratedly which shows a biased picture of the soccer games outcome on the stock market. When the scholars corrected the publications biases in this study,the scholars foundan insignificant result for national teams. In short, scholars provide a conflicting evidence against the welldiscussed hypothesis that stock market reactions are due to the sports sentiments. Mishra and Smyth, (2010)examine the association between the Indian cricket team's performance in ODI cricket against the Indian stock market returns and find an asymmetric association between the Indian cricket team performance and stock market returns. The scholars explore a conflicting result that when the Indian cricket team wins a match there is no significant upward trend in the stock market while a loss of the Indian cricket team shows a significant downward trend in the Indian stock market. And most particularly, the scholars of this study found that a huge downward movement in the Indian stock market is generated when SachinTendulkar plays in the match.

Eker, (2007) contributed to literature by studying the linkages between the sports performance during the matches of the Turkey national football teams and the economic growth in Turkey. The authors found a positive statistical correlation between the major football teams' success and theforeign exchange rate of Lira (Turkish) against the U.S dollar.Jegadeesh and Titman, (1993) investigated past winners and past looser stocks and provided evidence that the stocks which have performed poorly and stocks performed well during 3 to 12 months holding periods achieveda positive significant abnormal return. The authors have also documented a link for the past losers and past winners during the days of the earnings announcements. The same results have shown by De Bondt \& Thaler, (1987) with regards to stock price reversals. Kamstra, Kramer, \& Levi, (2003) investigated depression and seasonal affective disorder. The scholars defined the SAD that "a condition that affects many people during the seasons of relatively fewer hours of daylights". This study suggests the existence of sentimental effect during the winter depression or winter blues and equity returns in the stock markets. 
Andreff (2001) investigated a link between economic development in a country and its association with the sports events. The authors said that least developed countries are having no such financial and other resources to host sports events and provide a conducive environment to players so that they may take participation in the mega events like Olympic games. Hence, the author said that an ordered-logit model shows the probability for a country to win the medals at the Olympics increases positively with the increase in per capita and population. And this phenomenon is well depicted in a Spanish sentence "No Queremosgoals, Queremos frijoles" meaning that"we do not need goals, we need beans", clearly painted on the Mexico sports stadium during the Football World Cup in 1986. the authorsuggests that a low level of sports development in LDCs will trigger to a low-level of economic exposures and this clearly means that a rich country will hold all the aces during the mega sports events just because of their well economic development.

Around the globe, a volatility in the stock returns of Islamic mutual funds was investigated by Alrashidi, (2014) during the holy month of Ramadan. This month was particularly selected because the Muslims around the Globe enthusiastically follow the rituals of theholy month of Ramadan. The authors found no significant result in case of Islamic equity funds during the holy month of Ramadan. Nevertheless, the authors noticed that volatility decreased during the month of Ramadan but this change was not that much significant during the month.Hao, Dixon, and Wang, (2017) added that when a company announces new products in the market, the stock market will react to this announcement. Ultimately, investor sentiment plays avital role in determining the stock market reactions.By using the event study methodology, the authors considered new 227 product announcements of 155 Chinese companies during the time period starting from2006 to 2015 to study the association between investor sentiment and stock market reactions during the new product announcements. The authors find that new product announcements positively relate to stock market volatility. Moreover, the author said that in short run, higher investors sentiment strengthens the association between new product announcements and stock market reactions while negatively moderate it when the investor sentiment is lower in the stock market. As a result, the investor sentiment contributes to thestock market reaction during the new product announcement.

Yang, Ryu, and Ryu (2017)investigatedthat with respect to firm characteristics, investor sentiment affects the asset returns in Korean stock exchange. The authors confirmed the existence of anassociation between investor sentiment and stock market reactions and said that a high level of investor sentiment leads to a more volatility in stock returns. This association becomes more severe after controlling firm characteristics, individual trading behaviors and other risk associated with the firm. It is noticed that investor sentiment produces significant results in case of assets return when the firms are smaller, having low stock prices and high book to market ratio. Investor sentiment also induces stronger effects on thestock return when a firm usually produces high excess returns and having highly volatile stocks. 
Tian, (2017) said that high stock market reaction is very common in Chinese stock markets during the during the first day of Initial public offerings (IPO). The author said that under the traditional finance theory, it was not possible to study the association between IPO and stock market reactions, rather used behavioral finance theory from the investor sentiment perspective by applying Kalman filtering method to investigate the factors that contribute to IPO performance in China. The empirical results indicate that IPO shows underpricing in Chinese companies and investor sentiment proved to be the most significant factors that lead to excess returns in IPO. The author explored so many other factors like total quality, total assets, operating profit and cash flows, company age and offer avolume that could have acontribution in determining the excess stock market return in IPO.

\subsubsection{Pakistan Stock Market}

Several studies document the sports sentiments and stock market returns in U.S, Europe, and Asian countries but so far in Pakistan, no particular studies exist in theliterature. HoweverRaheman, Kiyani, Niaz, Sohail, and Zulfiqar, (2015) studied sports sentiment and volatility of stock returns in Pakistan stock exchange but this study was focused on International T20 and One day matches between Pakistan and Asian countries like India, Sri Lanka and Bangladesh during the study period 1992 to 2012. Only ODI matches have been studied by Naeem, (2015) where the scholar concludes that no significant association was found between the Pakistan Cricket Team performance in ODI and Karachi Stock Exchange.

In Pakistan, PSL event has become very popular and attracted spectators and investors during the first and second season. While founding no previous studies concerning the subject in thePakistani context, the Scholar selected the issue to conduct a research and makea considerable contribution for investors in Pakistan with respect to PSL events and its impact on PSX.

\section{Research Hypothesis}

Gratton, Dobson, and Shibli (2000) investigated major sports events in the United Kingdom in 1997 and showed significant impact on the economic growth in the stock market. Several studies have explored the impact of major sport events on the stock market returns in United States of America like Chang, Chen, Chou, and Lin (2012) studied National Football League against the NASDAQ firms and found significant evidence of the sport sentiments. Meanwhile, Guy Kaplanski and Haim Levy (2010) addressed the FIFA World Cup event and provided insignificant results in the US Stock markets. Furthermore, Bracewell, Bracewell, McNamara, and Moore (2017) discussed the Rugby World Cup of 2015 and said that the event has a significant impact on the behaviors of the New Zealanders when the game is won from Australia by All blacks. While is Europe, Samagaio, Couto, and Caiado (2009) investigated the association of sport performance, financial performance and stock returns for the English Football Clubs and provide a highly positive significant results. In short, studies in Europe about sports sentiments showed significant results, are provided by (Benkraiem and Roy (2011), Edmans, García, and Norli (2007), Brimicombe \& Cafe (2012), Saraç, M., 
and Zeren, (2013) and insignificant result by (Barajas, Fernandez-Jardon, And Crolley, (2005), Klein, Zwergel, \& Heiden, (2009), Fung, Demir, Lau, and Chan, (2015) and some Mixed conflicting results by (Floros, (2010), Ramdas, van Gaalen, and Bolton, (2015). Literature in Asia documented significant results of sport events and investor sentiment by (Refai and Eissa, (2017), Ryu, Kim, and Yang, (2017), Eker, (2007) and mixed results by (Geyer-Klingeberg, Hang, Walter, and Rathgeber, (2017), Mishra and Smyth, (2010) but in fact, in Pakistan, no such studies were found in literature on the burning issue of T-20 PSL. Therefore, an attempt is made to search out that is there any potential in the major sport events of PSL to generate an economic impact in the stock market?

$$
\begin{gathered}
\boldsymbol{H}_{\mathbf{0}}: \text { PSL has no significant impact on PSX. } \\
\boldsymbol{H}_{\mathbf{1}} \text { : PSL has a significant impact on PSX. }
\end{gathered}
$$

Null hypothesis means that investors are rational, markets are efficient and the economic benefit associated with PSL outcome is too small to influence the national stock market index. By alternative hypothesis, scholar explains that PSL event leads to a positive reaction of PSX. This is motivated by findings from the psychology literature which suggest that sports events are associated with mood swings.

\section{Research Methodology and Data Collection}

In this chapter, the scholar discusses empirical models and methodology process using the daily closing values ofPSX-100 index data. The scholar has adopted the event study methodology which is used by most of the scholars in the previous studies likeAshton, Gerrard, and Hudson (2003), Kumari and Mahakud, (2016). Moreover, the scholar uses dummy variables regression model where the scholar will assign two values of 0 and 1 (1for PSL event days and 0otherwise)considering for observations two financial years starting from June 2015 to July 2016 and June 2016 to July 2017.

The Scholarused secondary data of PSX-100 index daily closing values to determine the association between PSL event and PSX during the PSL first and second seasons. The scholar gatheredstock market data from Pakistan's major stock market which is Pakistan stock exchange for the period of two financial years starting from June 2015 to July 2017. PSL T20 data is collected from the website of Pakistansuperleague.com.pk.This website contains apool of information regarding the matches played during the whole PSL events.

\subsection{Variables of the Study}

This research investigates two variables, one dependent variable and the other is independent dummy variables. The dependent variable is PSX-100 index daily closing values which are transformed into mean returns. Independent dummy variable is the PSL event.

\subsection{Analytical Techniques}

The scholar used regression analysis to test which of the hypothesis holds true and false.in order to test the impact of PSL on PSX-100 index, two techniques are used (i) dummy variable regression model (ii) independent sample T-test to compare means of two PSL events in 2016-2017.A dummy variable is incorporated in the regression model as PSL(independent variable) has values of 0 
for normal days and 1 for event days and PSX-index closing values as the dependent variable.The percentage change in the returns of the index is used, Edmans et al., (2007). This regression analysis estimated the effects of the PSL events on the stock returns in PSX.

\subsection{Dummy Variable Regression Models and Independent Sample T-Test}

Dummy variables regression model is used in this study to analyze PSL event in PSX by considering thePSX-100 index daily closingvalues.In empirical results, if the coefficient ofPSL dummy variablesis significant then it exhibits the presence of sentimental effects inPSX during the seasons of PSL.For the existence of the sentimental effect, we use regression model of Edmans et al., (2007), Mishra and Smyth, (2010), Rees and Bersem, (2010), Chang et al., (2012), Floros, (2010)with a minor modification which is as follows;

\subsection{Regression Models}

$R_{t}=\beta_{0}+\beta_{1} P S L_{16}+\varepsilon_{t}(1)$

$R_{t}=\beta_{0}+\beta_{1} P S L_{17}+\varepsilon_{t}$ (2)

where $\boldsymbol{R}_{\boldsymbol{t}}$ is the daily $\log$ returns for the stock market index, $\boldsymbol{\beta}_{\mathbf{0}}$ is the intercept, $\boldsymbol{\beta}$ is used for OLS coefficient and $\boldsymbol{\varepsilon}_{\boldsymbol{t}}$ is the error term while remaining are the dummy variables;

$\boldsymbol{P S L}_{16}=$ Dummy variable $\mathrm{PSL}_{2016}$ take the value of 1 for event daysand 0 otherwise while $\boldsymbol{P S \boldsymbol { L } _ { \mathbf { 1 7 } }}=$ Dummy variable $\mathrm{PSL}_{2017}$ takes the value of 1 for event days and 0 otherwise.Thebasic motive behind the dummy variable regressionis to know whether there is any significant difference between the normal days and event days during the two PSL seasons in PSX.

If the results of our dummy variable regression model proved positive and significant then it would comply with the empirical results of Mishra and Smyth, (2010), Demir and Rigoni, (2017) and Edmans et al., (2007). If the results came outinsignificant it would comply with the empirical results of (Mishra \& Smyth, 2010, Geyer-Klingeberg et al., 2017).

The general model of the independent sample t-test is as follows;

$$
t=\frac{\left(\bar{x}_{1}-\bar{x}_{2}\right)-\left(\mu_{1}-\mu_{2}\right)}{\sqrt{S_{p}{ }^{2}\left(1 / n_{1}+1 / n_{2}\right)}}-\cdots-\text { (4) Eq. }
$$

Where $\sigma_{1}{ }^{2}=\sigma_{2}{ }^{2}$ with $n_{1}+n_{2}-2$ degree of freedom and

$$
S_{p}^{2}=\frac{\left(n_{1}-1\right) S_{1}^{2}+\left(n_{2}-1\right) S_{2}^{2}}{n_{1}+n_{2}-2}
$$

\subsection{Empirical Results and Analysis}

In onward sections of the empirical results and analysis, the scholar will debate about the results produced in the OLS regression and independent sample T-test. Evaluation and Interpretation of Empirical Results Of PSL-2016 
According to the methodology discussed earlier, the scholar runs two OLS regression model so that the scholar should measure the impact of PSL-2016 and PSL-2017 on the PSX respectively. First, the scholar run the dummy variable regression model for PSL-2016 as follows;

$P S X-100$ index $_{t}=\beta_{0}+\beta_{1} P S L_{16}+\varepsilon_{t}$

After running the regression, the following empirical results are produced which will be evaluated in terms of t-statistics, F-statistics and $\mathrm{R}^{2}$ in the following manner:

Table 2: Model Summary of Regression results of PSL-2016

\begin{tabular}{|c|c|c|c|c|}
\hline Model & $\mathrm{R}$ & R Square & $\begin{array}{l}\text { Adjusted R } \\
\text { Square }\end{array}$ & $\begin{array}{l}\text { Std. Error of } \\
\text { the Estimate }\end{array}$ \\
\hline 1 & $.298^{\mathrm{a}}$ & .089 & .085 & 1771.992 \\
\hline
\end{tabular}

Table 3: ANOVA ${ }^{a}$ results of Regression of PSL-2016

\begin{tabular}{llllll}
\hline Model & Sum of Squares & df & Mean Square & F & Sig. \\
\hline 1 Regression & 76042414.601 & 1 & 76042414.601 & 24.218 & $.000^{b}$ \\
Residual & 781849388.688 & 249 & 3139957.384 & & \\
Total & 857891803.289 & 250 & & & \\
\hline
\end{tabular}

a. Dependent Variable: PSX-100 Index

b. Predictors: (Constant), PSL-2016

Table 4: Coefficients ${ }^{a}$ of Regression result of PSL-2016

\begin{tabular}{|c|c|c|c|c|c|c|}
\hline \multirow[b]{2}{*}{ Model } & & \multicolumn{2}{|c|}{ Unstandardized Coefficients } & \multirow{2}{*}{$\begin{array}{c}\text { Standardized } \\
\text { Coefficients } \\
\text { Beta }\end{array}$} & \multirow[b]{2}{*}{$\mathrm{t}$} & \multirow[b]{2}{*}{ Sig. } \\
\hline & & $\mathrm{B}$ & Std. Error & & & \\
\hline 1 & (Constant) & 34150.354 & 114.861 & & 297.318 & .000 \\
\hline & PSL-2016 & -2483.732 & 504.706 & -.298 & -4.921 & .000 \\
\hline
\end{tabular}

a. Dependent Variable: PSX-100 Index

Reporting of empirical results of dummy variable regression model for 2017

$$
\begin{aligned}
& P S X-100 \text { index }=\beta_{0}+\beta_{1} P S L_{16}+\varepsilon_{t} \\
& P S X-100 \text { index }=\beta_{0}+\beta_{1} P S L_{16}+\varepsilon_{t} \\
& =34150.354-2483.732 \text { PSL }_{16} \\
& \text { (114.861) (504.706) (Standard Error) } \\
& \text { (297.318) (-4.921) (t-statistic) } \\
& \text { (0.000) (0.000) (p-value/sig. level) } \\
& \mathrm{R}=.298 \mathrm{R}^{2}=0.089 \quad \mathrm{R}_{\text {adjusted }}^{2}=0.085
\end{aligned}
$$




$$
\mathrm{F}=24.218(\mathrm{p} \text {-value }=0.000) \quad \mathrm{N}=251
$$

The above Tables 2-4 show that dummy variable regression model for PSL-2016 as a whole is statistically significant at $\mathrm{F}=24.218$ at $\alpha<0.01$; however, only 8.5 percent variation in PSX-100 index has been explained by the event of PSL-2016 included therein. As far as an individual explanatory variable (PSL-2016) is concerned, it is statistically significant at $\alpha<0.01$. The empirical results in Table 4.2.3 indicate that the average of the PSX-100 index normal days is 34150.354 thousand, while that of during the PSL-2016 event days is less than the normal days by 2483.732 thousand. It is to be noted that this difference of PSX-100 index during the event days is highly statistically significant at $\alpha<0.01$. it is very clear in the empirical results after running the Dummy variable regression that PSL2016 event is negligibly contributing to PSX-100 index closing value, indicating that PSL-2016 whole season was played out of the country and hence, the PSX did not outperform during the first season of PSL in 2016.

Evaluation and Interpretation of Empirical Results of PSL-2017

Table 5: Model summary of Regression results of PSL-2017

\begin{tabular}{lcccc}
\hline Model & $\mathrm{R}$ & $\mathrm{R}$ Square & $\begin{array}{c}\text { Adjusted R } \\
\text { Square }\end{array}$ & $\begin{array}{c}\text { Std. Error of } \\
\text { the Estimate }\end{array}$ \\
\hline 1 & $.255^{\text {a }}$ & .065 & .061 & 4207.599 \\
\hline a. Predictors: (Constant), PSL-2017 \\
b. Dependent Variable: PSX-100 Index
\end{tabular}

Table 6: ANOVA ${ }^{a}$ results of Regression of PSL-2017

\begin{tabular}{|c|c|c|c|c|c|}
\hline Model & Sum of Squares & $\mathrm{df}$ & Mean Square & $\mathrm{F}$ & Sig. \\
\hline 1 Regression & 297090851.260 & 1 & 297090851.260 & 16.781 & $.000^{\mathrm{b}}$ \\
\hline Residual & 4284342232.594 & 242 & 17703893.523 & & \\
\hline Total & 4581433083.85 & 243 & & & \\
\hline
\end{tabular}

a. Dependent Variable: PSX-100 Index

b. Predictors: (Constant), PSL-2017

Table 7: Coefficients ${ }^{a}$ of Regression of PSL-2017

\begin{tabular}{lllllll}
\hline \multicolumn{2}{c}{} & \multicolumn{2}{c}{ Unstandardized Coefficients } & \multicolumn{2}{c}{ Coefficients } \\
\multicolumn{2}{c}{ Model } & \multicolumn{1}{c}{ B } & Std. Error & Beta & t & Sig. \\
\hline 1 & (Constant) & 45086.615 & 279.885 & & 161.090 & .000 \\
& PSL-2017 & 4221.328 & 1030.478 & .255 & 4.096 & .000 \\
\hline
\end{tabular}

a. Dependent Variable: PSX-100 Index 
Evaluation and interpretation of empirical results of PSL-2017

The above tables 4.4.1 and 4.4.2 show that dummy variable regression model for PSL-2017 as a whole is highly statistically significant at $\mathrm{F}=16.781$ at $\alpha=$ 0.000; however, only 6.5 percent variation in PSX-100 index has been explained by the event of PSL-2017 included therein. As far as an individual explanatory variable (PSL-2017) is concerned, it is statistically significant at $\alpha<0.01$. The empirical results in Table 4.4.3 indicate that the average volume of the PSX-100 index normal days is 45086.615 thousand, while that of during the PSL-2016 event days is greater than the normal days by 4221.328 thousand. It is to be noted that this difference of PSX-100 index during the event days is highly statistically significant at $\alpha<0.01$. it is very clear in the empirical results after running the Dummy variable regression that PSL-2017 event contributes positively significantly to PSX-100 index closing value, indicating that PSL2017 final was played in Lahore, Pakistan, that is the reason that PSX-100 index outperformed during the event of PSL-2017.

Independent sample t-test empirical results for PSL-2016

This test is carried out to reassess the association between PSL-2016 eventand PSX-100 index closing values to know about the reaction of the stock market returns. The independent sample t-test results for PSL-2016 is given below;

Table 4.5. 1: Group Statistics of PSL-2016 (Panel-A)

\begin{tabular}{llccll} 
& PSL-2016 & N & Mean & Std. Deviation & Std. Error Mean \\
\hline PSX-100 Index & Event Days & 13 & 31666.62 & 677.912 & 188.019 \\
& Normal Days & 238 & 34150.35 & 1809.882 & 117.317
\end{tabular}

Table 4.5. 2: Independent Sample Test of PSL-2016 (Panel-B)

Levene's
Test for
Equality
of
Variance
s t-test for Equality of Means

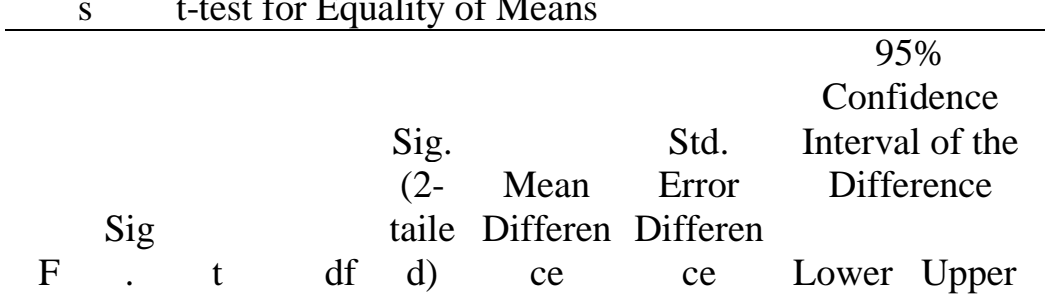




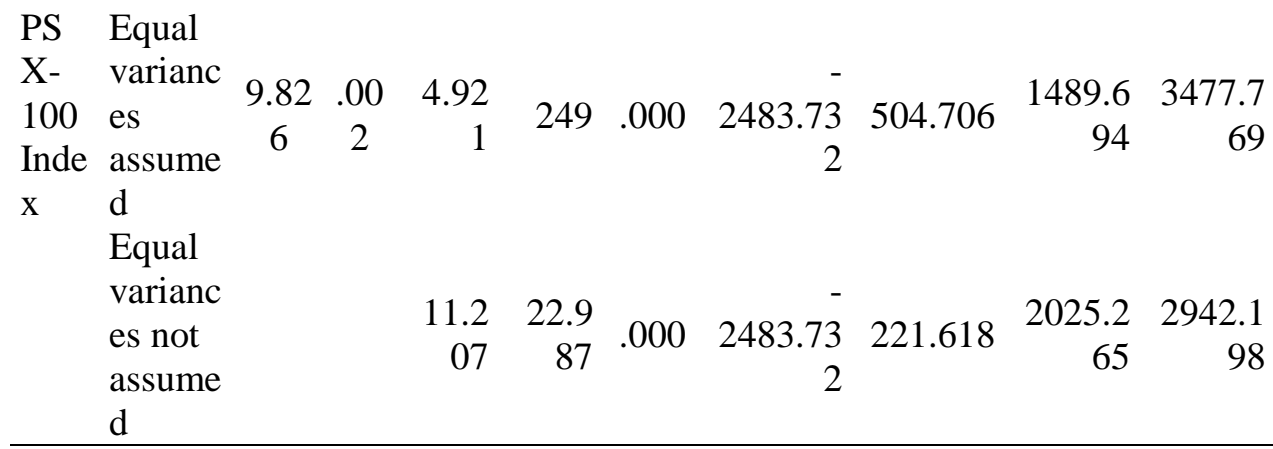

Reporting of results of dummy variable regression model for 2017

$$
\begin{array}{r}
\text { PSX - 100 index }=\boldsymbol{\beta}_{\mathbf{0}} \quad+\boldsymbol{\beta}_{\mathbf{1}} \boldsymbol{P S L _ { 1 7 }}+\boldsymbol{\varepsilon}_{\boldsymbol{t}} \\
=45086.615+4221.328 \boldsymbol{P S L _ { 1 7 }}
\end{array}
$$

The independent sample t-test results are divided into (a) and (b) panels.Panel (a) of Table 5.3 shows the results of the event of PSL-2016 that the mean of PSX-100 index during normal days is 34150.35 while that of event days estimates at 31666.62. Hence, there is a mean difference of -2483.732 and this mean difference is highly statistically significant at $\mathrm{t}=-11.207$ at $\mathrm{p}=.000$.

Panel (b) of table 5.3 produced Levene's test for equality of variances which is the pre-test for the use of independent sample t-test which estimates $F=9.826$ at $p=$ .002 , suggesting that $\mathrm{F}$ is statistically significant so the two variances of the normal days and event days for PSL-2016 are not equal and alike. Hence, the ttest results provided in the second row is valid which suggest that there is a statistically significant impact of PSL on PSX but this time this impact is negative instead of positive because the whole PSL-2016 season was played outside the country and therefore, PSX negatively reacted to thePSL-2016 event.As we can see the mean difference between the normal days and event days during the PSL matches in the year of 2016. Hence, thealternate hypothesis is accepted in case of PSL-2016 and PSX.

Independent sample t-test empirical results for PSL-2017

Table 4.6. 1: Group Statistics of PSL-2017 (Panel-A)

\begin{tabular}{llrrrr} 
& & & & & \multicolumn{2}{c}{$\begin{array}{c}\text { Std. Error } \\
\text { Mean }\end{array}$} \\
\hline PSX-100 Index & Event Days & 18 & 49307.94 & 456.833 & 107.677
\end{tabular}


Normal Days $226 \quad 45086.61 \quad 4361.852 \quad 290.146$

Table 4.6. 2: Independent Sample Test of PSL-2017 (Panel-B)

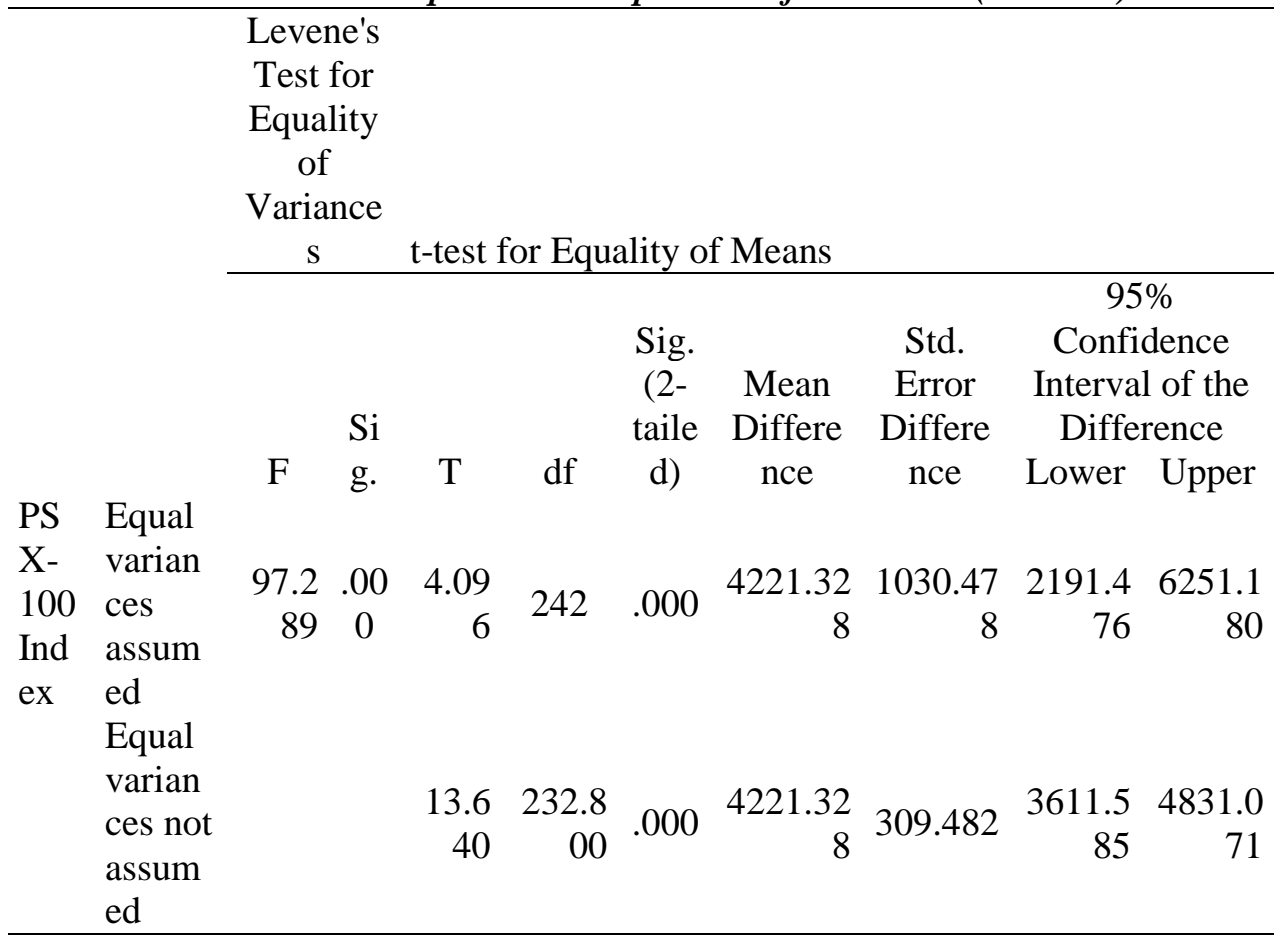

The independent sample t-test results are divided into (a) and (b) panels.Panel (a) of Table 5.3 shows the results of the event of PSL-2017 that the mean of PSX-100 index during normal days is 45086.61 pointswhile that of event days estimates at 49307.94 points. Hence, there is a positive mean difference of 4221.328 points and this mean difference is highly statistically significant at $\mathrm{t}=13.640$ at $\mathrm{p}=.000$.

Panel (b) of table 5.3 produced Levene's test for equality of variances which is the pre-test for the use of independent sample t-test which estimates $\mathrm{F}=9.826$ at $\mathrm{p}=$ .002 , suggesting that $\mathrm{F}$ is statistically significant so the two variances of the normal days and event days for PSL-2016 are not equal and alike. Hence, the ttest results provided in the second row is valid which suggests that there is a statistically significant impact of PSL on PSX but this time this impact is positive because the final of PSL-2017 was played in Lahore, Pakistan. Therefore, PSX positively reacted to the event of PSL in 2017. As we can see the mean difference between the normal days and event days during the PSL matches in the year of 2017. Hence, the alternate hypothesis is accepted in case of PSL-2017 and PSX.

\section{Discussion and Conclusion}

In this current study, the scholar addresses a continuous debate about the association between Pakistan Super League and its impact on the Pakistan Stock 
Exchange in the investor sentiment literature from a behavioral perspective. As literature is full of investor sentiment debate and discussed the issue very broadly that certain different events lead to investor sentiment (Mishra \& Smyth, 2010;Demir \& Rigoni, 2017;Edmans, García, \& Norli, 2007; Bracewell, Bracewell, McNamara, \& Moore, 2017). Using the two financial years data of PSX-100 index starting from June 2015 to July 2017 which will cover the two PSL seasons.

The scholar divides the conclusion in terms of dummy variable regression and independent sample t-test. First, dummy variable regression model results showed that PSX reacted sharply negatively during the event days of PSL in the year of 2016 which leads to a negative 2483 thousand points in PSX-100 index and positively this result of the scholar in the current study is consistent with the outcome of the (Fung, Demir, Lau, \& Chan, 2015; Ramdas, van Gaalen, \& Bolton, 2015; Ryu, Kim, \& Yang, 2017; Geyer-Klingeberg, Hang, Walter, \& Rathgeber, 2017)while PSL 2017has a highly positive significant impact on PSX by having a positive 4221.328 thousand points in PSX-100 index and this outcome of the scholar in this study is accurately consistent with the findings of the(Saraç, \& Zeren, 2013;Chang, Chen, Chou, \& Lin, 2012; Bracewell, Bracewell, McNamara, \& Moore, 2017; Hirshleifer \& Shumway, 2003; Benkraiem \& Roy, 2011).On the other hand, in order to retest the association between PSL event and PSX-100 index, the independent sample t-test is used. The Independent sample ttest also produced the same results in terms of PSL 2016-2017 and PSX-100 index. Independent sample t-test of PSL-2016 produced a negative mean difference of 2483.732 thousand points in PSX-100 index and the same result was provided by Edmans, García, \& Norli, (2007)while t-test for PSL-2017 provided that there is a positive mean difference of 4221.328 thousand points in PSX-100 index during the event days and this outcome concurs with the findings obtained by Jegadeesh \& Titman, (1993).

On the basis of the empirical results, the scholar concludes that Pakistan super league events have somewhat a highly significant negative and positive impact on Pakistan stock exchange 100-index during the study period of two financial years starting from June 2015 to July 2017.In this course of study, the alternate hypothesis is accepted that PSL event has a significant impact on PSX while rejected the Null hypothesis of PSL event has no significant impact on PSX-100 index.

\subsection{Recommendations and future directions of the study}

On the basis of the empirical results of PSL 2016 and 2017 produced in the OLS dummy variable regression and independent sample t-test, the scholar suggests the competent authoritiesto place the PSL only two seasons old on the top of the World popular T20 leagues. First, strictly hosting the PSL event by Pakistan inside the country as venue matters a lot in making it significant in terms of growth in the economy. Second, there should be more teams to have more contribution in making the PSL event more popular and to attract more sponsors. Third, PCB should make it possible to increase the number of matches and total length of the event to generate sentiments on the longer basis. Fifth, PCB and 
franchises should attract more international icon cricketers by allowing them high remuneration and bonuses. Future researchers nevertheless are still required in this broad area of Sports sentiment in Pakistan where by other relevant variables and more sophisticated statistical variables are applied. Apart from this research, the future researchers can concentrate on a comparable study of Indian Premier League T-20 and Pakistan Super League T-20 against their respective stock market return. In order to know the significant picture of the PSL, the future researchers may investigate whether the number of international icon players does matter in determining the association of PSL and Pakistan Stock exchange. In the meanwhile, the future researchers may study the pre and post impact of PSL on the economic growth of Pakistan. The researchers can also concentrate by analyzing the impact of PSL on the economic growth in Pakistan with a mediating effect of different venues inside and outside Pakistan.

\section{References}

Adjei, f., \& adjei, m. (2017). Political cycles, investor sentiment, and stock market return. Journal of finance and economics, 5(1), 1-10.

Https://doi.org/10.12691/jfe-5-1-1

Alrashidi, f. (2014). The calendar impact and trading behavior: an empirical evidence from around the globe. International business \& economics research journal, 13(5).

Andreff, w. (2001). The correlation between economic underdevelopment and sport. European sports management quarterly, 1(4), 251-279. Https://doi.org/10.1080/16184740108721902

Ashton, j. K., gerrard, b., \& hudson, r. (2003). The economic impact of national sporting success: evidence from the london stock exchange. Applied economics letters, 10(12), 783-785.

Baker, h kent; nofsinger, j. R. (2002). The psychological bias of investors.pdf. Financial services review; atlanta, 11(2), 97-116.

Balcilar, m., bonato, m., demirer, r., \& gupta, r. (2017). The effect of investor sentiment on gold market return dynamics: evidence from a nonparametric causality-in-quantiles approach. Resources policy, 51, 77-84. Https://doi.org/10.1016/j.resourpol.2016.11.009

Benkraiem, r., \& roy, f. Le. (2011). Sporting performances and the volatility of listed football clubs. International journal of sports finance, (6), 283-297.

Bracewell, p., bracewell, p. J., mcnamara, t. S., \& moore, w. E. (2017). How rugby moved the mood of new zealand. Journal of sport and human performance, 4(4). Https://doi.org/10.12922/jshp.v4i4.93

Brealey, ra, myers, sc \& marcus, a. (2009). Fundamentals of corporate finance (8th ed.). Mcgraw-hill, new york.

Brimicombe, a., \& cafe, r. (2012). Beware, win or lose: domestic violence and the world cup. Significance, 9(5), 32-35. Https://doi.org/10.1111/j.17409713.2012.00606.x

Chang, s.-c., chen, s.-s., chou, r. K., \& lin, y.-h. (2012). Local sports sentiment and returns of locally headquartered stocks: a firm-level analysis. Journal of empirical 
finance, 19(3), 309-318. Https://doi.org/10.1016/j.jempfin.2011.12.005

De bondt, w. F. M., \& thaler, r. H. (1987). Further evidence on investor overreaction and stock market seasonality. Journal of finance, 42(3), 557581. Https://doi.org/10.2307/2328371

Demir, e., \& rigoni, u. (2017). You lose, i feel better. Journal of sports economics, 18(1), 58-76. Https://doi.org/10.1177/1527002514551801

Duque, j. L., \& ferreira, n. A. (2005). Explaining share price performance of football clubs listed on the euronext lisbon. Ssrn electronic journal, (working papers no. 05-01), 38. Https://doi.org/10.2139/ssrn.675633

Edmans, a., garcía, d., \& norli, Ø. (2007). Sports sentiment and stock returns. The journal of finance, 62(4), 1967-1998. Https://doi.org/10.1111/j.15406261.2007.01262.x

Eker, g. (2007). Football and exchange rates: empirical support for behavioral economics. Psychological reports, 643. Https://doi.org/10.2466/pr0.101.6.643-654

Floros, c. (2010). The impact of the athens olympic games on the athens stock exchange. Journal of economics studies, 37(6), 647-657. Https://doi.org/10.1108/01443581011086675

Fung, k. W. T., demir, e., lau, c. K. M., \& chan, k. H. (2015). Reexamining sports-sentiment hypothesis: microeconomic evidences from borsa istanbul. Journal of international financial markets, institutions and money, 34, 337-355. Https://doi.org/10.1016/j.intfin.2014.11.015

Geyer-klingberg, j., hang, m., walter, m., \& rathgeber, a. (2017). Do stock markets react to soccer games? A meta-regression analysis. Ssrn electronic journal, 38. Https://doi.org/10.2139/ssrn.2800979

Gratton, c., dobson, n., \& shibli, s. (2000). The economic importance of major sports events: a case-study of six events. Managing leisure, 5(1), 17-28. Https://doi.org/10.1080/136067100375713

Guy kaplanski and haim levy. (2010). Exploitable predictable irrationality: the fifa world cup effect on the u.s. Stock market. Journal of financial and quantitative analysis, 45(2), 535-553. Https://doi.org/10.1017

Hao, f., dixon, r., \& wang, t. (2017). Stock market reactions to new product announcements: the role of investor sentiment. The business and management review, 8(4).

Haug, m., \& hirschey, m. (2006, september 11). The january effect. Financial analysts journal. Cfa institute. Https://doi.org/10.2469/faj.v62.n5.4284

Hensel, c. R., \& ziemba, w. T. (1995). United states investment returns during democratic and republican administrations, 1928-1993. Financial analysts journal, 51(2), 61-69. Https://doi.org/10.2469/faj.v51.n2.1882

Hirshleifer, d. (2001). Investor psychology and asset pricing. The journal of finance, 56(4), 1533-1597. Https://doi.org/10.1111/0022-1082.00379

Hirshleifer, d., \& shumway, t. (2003, june 1). Good day sunshine: stock returns and the weather. Journal of finance. Blackwell publishing inc. Https://doi.org/10.1111/1540-6261.00556

Holmes-galloway, a., \& khaled, m. (2017). Rugby results and investor sentiment 
in new zealand.

Huang, r. (1985). Common stock returns and presidential elections. Financial analysts journal, 41(2), 58-61. Https://doi.org/10.2469/faj.v41.n2.58

Jegadeesh, n., \& titman, s. (1993). Returns to buying winners and selling losers: implications for stock market efficiency. The journal of finance, 48(1), 65-91. Https://doi.org/10.1111/j.1540-6261.1993.tb04702.x

Jiang, y., mo, b., \& nie, h. (2017, june 16). Does investor sentiment dynamically impact stock returns from different investor horizons? Evidence from the us stock market using a multi-scale method. Applied economics letters, pp. 1-5. Https://doi.org/10.1080/13504851.2017.1340558

Kamstra, m. J., kramer, 1. A., \& levi, m. D. (2003). Winter blues: a sad stock market cycle. The american economic review, 93121(1), 324-343. Https://doi.org/10.2307/3132178

Kaplanski, g., levy, h., veld, c., \& veld-merkoulova, y. (2015). Do happy people make optimistic investors? Journal of financial and quantitative analysis, 50(1-2), 145-168. Https://doi.org/10.1017/s0022109014000416

Klein, c., zwergel, b., \& heiden, s. (2009). On the existence of sports sentiment: the relation between football match results and stock index returns in europe. Review of managerial science, 3(3), 191-208. Https://doi.org/10.1007/s11846009-0031-8

Kumari, j., \& mahakud, j. (2016). Investor sentiment and stock market volatility: Evidence from india. Journal of asia-pacific business. Retrieved from http://www.tandfonline.com/doi/abs/10.1080/10599231.2016.1166024

Mcconnell, j. J., \& wei, x. (2008). Equity returns at the turn of the month. Financial analysts journal, 64(2), 49-64. Https://doi.org/10.2469/faj.v64.n2.11

Mishra, v., \& smyth, r. (2010). An examination of the impact of india's performance in one-day cricket internationals on the indian stock market. Pacificbasin finance journal, 18(3), 319-334. Https://doi.org/10.1016/j.pacfin.2010.02.005

Naeem, m. (2015). An analysis of the impact of pakistan's cricket team performance in one day internationals (odis) on kse: a behavioral finance perspective. International journal of innovative knowledge concepts, 3(4). Retrieved from http://ijikc.co.in/sites/ijikc/index.php/ijikc/article/view/75

Namouri, h., jawadi, f., ftiti, z., \& hachicha, n. (2018). Threshold effect in the relationship between investor sentiment and stock market returns: a pstr specification. Applied economics, 50(5), 559-573. https://doi.org/10.1080/00036846.2017.1335387

Pompian, m. (2012). Behavioral finance and investor types: managing behavior to make better investment decisions. Wiley.

Raheman, a., kiyani, a., niaz, s., sohail, m. K., \& zulfiqar, b. (2015). Sports and stock returns volatility: a case of cricket matches played by pakistan with asian countries. Sci.int.(lahore), 27(3), 2623-2632. Retrieved from http://www.sciint.com/pdf/16876880582623 2632 abdul raheman-2-ss--rwd .pdf.

Ramdas, b., van gaalen, r., \& bolton, j. (2015). The announcement impact of hosting the fifa world cup on host country stock markets. Procedia economics and 
finance, 30(15), 226-238. Https://doi.org/10.1016/s2212-5671(15)01290-3

Rees, n. Van, \& bersem, d. (2010). Sports sentiment and stock returns. Retrieved from http://dare.uva.nl/cgi/arno/show.cgi?fid=169129

Refai, h. Al, \& eissa, m. A. (2017). The impact of fifa's official announcements on the stock market of qatar: the case of the 2022 world cup. Research in international business and finance, 41, 347-353. Https://doi.org/10.1016/j.ribaf.2017.04.032

Ryu, d., kim, h., \& yang, h. (2017). Investor sentiment, trading behavior, and stock returns. Applied economics letters, 24(12), 826-830. Https://doi.org/10.1080/13504851.2016.1231890

Samagaio, a., couto, e., \& caiado, j. (2009). Sporting, financial and stock market performance in english football: an empirical analysis of structural relationships. English.

Saraç, m., \& zeren, f. (2013). No the effect of soccer performance on stock return: empirical evidence from "the big three clubs" of turkish soccer league. Journal of applied finance and banking, 3(5), 299-314

Schmidt, d., barberis, n., djordjevic, m., dumas, b., fang, 1., grin, j., ... xiong, w. (2013). Investors' attention and stock covariation evidence from google sports searches i thank joël press for his constant guidance and support. I further.

Seif, m., docherty, p., \& shamsuddin, a. (2017). Seasonal anomalies in advanced emerging stock markets. The quarterly review of economics and finance, 66, 169181. Https://doi.org/10.1016/j.qref.2017.02.009

Shiller, r. J. (2003). From efficient markets theory to behavioral finance. Journal of economic perspectives, 17(1), 83-104.

Https://doi.org/10.1257/089533003321164967

Shiller, r. J. (2015). Irrational exuberance revisited. Cfa institute conference proceedings quarterly (3rd ed., vol. 23). Princeton university press. Https://doi.org/10.2469/cp.v23.n3.4255

Siganos, a., vagenas-nanos, e., \& verwijmeren, p. (2017). The divergence of sentiment and stock market trading. Journal of banking \& finance, 78, 130-141. Https://doi.org/10.1016/j.jbankfin.2017.02.005

Statman, m. (1999). Behavioral finance: past battles and future engagements on jstor. Financial analysts journal, 55(6), 18-27. Retrieved from http://www.jstor.org/stable/4480206?seq=1\#page_scan_tab_contents

Sun, 1., najand, m., \& shen, j. (2016). Stock return predictability and investor sentiment: a high-frequency perspective. Journal of banking and finance, 73, 147164. Https://doi.org/10.1016/j.jbankfin.2016.09.010

Tian, 1. (2017). Investor sentiment on the first day excess returns of initial public offerings. Boletín técnico, 55(9), 728-736.

Wright, w. F., \& bower, g. H. (1992). Mood effects on subjective probability assessment. Organizational behavior and human decision processes, 52(2), 276291. Https://doi.org/10.1016/0749-5978(92)90039-a

Yang, h., ryu, d., \& ryu, d. (2017). Investor sentiment, asset returns, and firm characteristics: evidence from the korean stock market. Investment analysts journal, 46(2), 132-147. Https://doi.org/10.1080/10293523.2016.1277850 